\title{
Nutritional Education Tool to Improve Overall Dietary Attitude and Knowledge among Young Women
}

\author{
Neena Joshi and K. G. Vijayalaxmi \\ Agricultural Technology Information Centre, University of Agricultural Sciences, Hebbal \\ Campus, Bangalore 560 024, Karnataka, India
}

KEYWORDS Intervention. Mal Nutrition. Knowledge. Nutrition Education. Community Perception

\begin{abstract}
One of the weakest links in intervention programs to control malnutrition is the absence of proper nutrition education. Scarcity of appropriate and specific education material is weakness in Nutrition Education endeavours.As part of a community nutrition education program, nutrition education material in the form of a booklet was prepared keeping in view the updated scientific information. Qualitative research techniques such as focus group discussion and focused ethnography utilized to assess the existing community perception, beliefs to identify attitude preferences and resistance factors. Simple messages were prepared by reconstructing themes. Fifty-two women constituting two groups participated in the study. Women in Group-A, were those who had a tangible information seeking attitude, these were Farmers Training Institute trainees and those in Group-B were those who had never been exposed to any outside extension program, these were farm women of Kurubarahalli.The impact of the nutrition education tool was assessed by a check list of 31 questions. Significant improvements in knowledge was observed in all variables in both groups. Study demonstrated that nutrition and health related messages incorporated in the education material successfully transmitted to the target group of women.
\end{abstract}

\section{INTRODUCTION}

Nutrient deficiency is one of the major current nutritional concerns faced by the Indian Society; controlling nutrient deficiency is one of the direct interventions enshrined in the National Nutritional Policy (Ramji, 1994). Positive role of nutrition in improving the nutrition and health indicators have been demonstrated in both developed as well as developing countries. Role of education is positive in prognosis of pregnancy (Dyson et al. 1991), nutrition knowledge (Anderson et al. 1995) and nutrient intakes among pregnant women (Kafatos 1989). Kaur and Chawla (2006) found nutrition counseling was effective in bringing about modifications in changing knowledge, attitude and practices of subjects belonging to upper-middle income class. Even among Low Socio Economic Group (LSEG), nutrition education to women positively influenced the intake of soybeans (Deshpande and Bargale 2006). Bhat et al. (1992) found that

Address for Correspondence:

Mrs.Vijayalaxmi.K.G., Assistant Professor (Sr. Scale)

Agricultural Technology Information Centre, University of Agricultural Sciences, Hebbal Campus, Bangalore 560024 Karnataka, India

Telephone: 23513093/23549687

E-mail:vijayalaxmivinod@gmail.com/

vijayalaxmivinod@yahoo.com degree of maternal awareness found to have a direct relationship with infant nutrition. National plan of action on nutrition also considers empowering women with nutrition education. At the same time food based approach is now widely accepted as more desirable and sustainable method of preventing micronutrient malnutrition (Buyekx 1993).

Effective utilization of information, education and communication strategies are at the core of nutrition education. It recognized well as one of the weakest links in intervention programs to control mal-nutrition (Nayak et al. 1999). Community participation is now advocated as a key factor to reduce malnutrition. Gillespie (1996) is of the view that, information tends to be more optimally used; in a more timely manner at the level; it generated, particularly when the people who collect the data are those who use it.

Scarcity of appropriate location-specific educational material is a weakness of nutrition education endeavors (Saibaba and Raghuram 1999).Therefore location-specific nutrition education material was prepared after conducting sound formative research work. The objective of the present study was to test methodically, whether nutrition and health related messages incorporated in the educational material successfully transmitted to the target group of women. 


\section{MATERIAL AND METHODS}

Sample: The study was located in one of the of the villages in Bangalore Urban District and Farmers Training Institute, where farm women from Bangalore Urban and rural districts had come to undergo training in agriculture. Young women (age group of 18-31 y) constituted the sample for formative research $(n=30)$. All women belonged to the low socio-economic group. Responses of the formative research survey formed the basis on which the messages were prepared for evaluation. For the purpose of evaluation, different set of women from the same source was used. Based on the location of the women they were treated as two distinct groups. Women in Group-A $(n=27)$, were those who had information seeking behaviour while in Group-B $(n=25)$ were those who had not been exposed to any training programs away from their homes.

Formative Research: Mothers were interviewed with the help of pre-tested interview schedule drawn for the purpose in their homes. Based on the above, significant variables were selected for drawing the list of nutrition messages to be included in the booklet.

Preparation of the Booklet: Booklet was prepared based on formative research conducted for the purpose. The nutrition messages were incorporated in the booklet. Booklet was prepared in the local language i.e., Kannada.Booklet was divided into 11 parts. Seven chapters were devoted to different stages of early childhood and included information on dietary advice, hygiene and sanitation, immunization, ideal weight for age and developmental milestones during different stages of childhood. One chapter each was devoted to management during diarrhea, preparation of low cost weaning food, diet during pregnancy and dehydration of vegetables. After the booklet was prepared it was pre-tested on a group of five women to make it comprehensive. These women were excluded at later stage from the study.

Evaluation of Booklet: Women who could read asked to assemble in a quiet room and they were asked a set of pre-tested questions before they were asked to read the booklet to assess the baseline levels of knowledge (baseline scores). Then they read the booklet. At the end of the reading session, they were allowed to have free discussion with the facilitator. For mothers who could not read chapters from the booklet was read out by the facilitator. Thereafter these women also participated in a discussion about the booklet. The whole process lasted for about a week. At the end of the week, women were interviewed to answer the pre-tested structured questions about the lessons they had read/heard during the previous week to determine the post-intervention knowledge levels (Post-intervention scores).For each of the information/statements scores were assigned to responses (Correct response-3, no response-2 and wrong response-1).Entire procedure took about two weeks to complete. In all women had to answer 31 questions.

Analysis of Data: Baseline/post, intervention scores of women in each group were analyzed and the means used for statistical analysis. The modified ' $t$ ' test and correlation co-efficient were the statistical measures employed in the study.

\section{RESULTS AND DISCUSSION}

Background information of the women is depicted in Table 1. All were rural women aged between 20 and $31 \mathrm{y}$, belonged to the lower socioeconomic group. Around eight percent of the women were illiterate; remaining had a minimum primary level of education. Source of information about child rearing and related practices were reported to be mainly television, health worker and radio.

Apart from T.V., the source of information was mainly health workers. This is in line with the opinion expressed by the experts in the area of community nutrition (Gillespie 1994). This justifies developing of nutrition education tools at community level as has been attempted in this study.

Mean scores of the levels of knowledge achieved by the women of group A and B for 31

Table 1: Background information about the women

\begin{tabular}{|c|c|c|c|c|}
\hline \multirow[t]{2}{*}{ Variables } & \multicolumn{2}{|c|}{ Group-A } & \multicolumn{2}{|c|}{ Group-B } \\
\hline & Mean & $S D$ & Mean & $S D$ \\
\hline Age (in years) & 23.2 & 4.2 & 25.2 & 6.54 \\
\hline Education ${ }^{\mathrm{a}}$ & 2.8 & 0.9 & 2.6 & 0.90 \\
\hline Number of children & 2.2 & 0.7 & 1.9 & 0.29 \\
\hline Land holding(acres) & 2.1 & 2 & 1.5 & 1.10 \\
\hline \multicolumn{5}{|c|}{ Source of Information (\%) } \\
\hline Television & 100 & 0 & 77 & 0.43 \\
\hline Health worker & 80 & 0.4 & 72 & 0.46 \\
\hline Print Media & 32 & 0.7 & 36 & 0.49 \\
\hline School & 0 & 0 & 9 & 0.29 \\
\hline Radio & 24 & 0.5 & 59 & 0.50 \\
\hline
\end{tabular}

a-education was rated on a 3 point continuum where$1=$ illiterate; 2 =primary education; $3=$ secondary education 
Table 2: Mean scores of knowledge levels of women with tangible information seeking behavior ( $\mathbf{n = 2 5})$

\begin{tabular}{|c|c|c|c|c|c|}
\hline \multirow[t]{3}{*}{ Baseline scores } & \multicolumn{4}{|c|}{ Scores of Group A } & \multirow[b]{3}{*}{ ' $t$ ' value } \\
\hline & \multicolumn{2}{|c|}{ Base Line } & \multicolumn{2}{|c|}{ Post-Intervention } & \\
\hline & Mean & $S E$ & Mean & $S E$ & \\
\hline \multicolumn{6}{|l|}{ Medium Baselines Scores } \\
\hline Tetanus shots in pregnancy & 2.4 & 0.34 & 2.9 & 0.06 & $4.08 * * *$ \\
\hline Health check-ups in pregnancy & 2.2 & 0.30 & 2.6 & 0.11 & $3.89 * * *$ \\
\hline Birth Spacing & 2.2 & 0.30 & 2.7 & 0.10 & $5.25 * * *$ \\
\hline Diet in pregnancy & 2.2 & 0.30 & 2.6 & 0.11 & $4.76 * * *$ \\
\hline First breast feed & 2.4 & 0.33 & 2.9 & 0.06 & $4.56 * * *$ \\
\hline Complementary feeding & 2.3 & 0.32 & 2.8 & 0.08 & $4.36 * * *$ \\
\hline On-demand breast feeding & 2.6 & 0.36 & 3.0 & 0.03 & $2.75 * *$ \\
\hline Immunization Schedule & 2.4 & 0.33 & 2.6 & 0.11 & $2.37 * *$ \\
\hline Birth Weight & 2.1 & 0.29 & 2.6 & 0.10 & $5.42 * * *$ \\
\hline Estimation of child's weight & 2.0 & 0.28 & 2.2 & 0.06 & $2.50 * *$ \\
\hline Developmental milestones-3 & 2.0 & 0.28 & 2.8 & 0.08 & $9.30 * * *$ \\
\hline Developmental milestones- 4 & 2.0 & 0.28 & 2.9 & 0.06 & $11.49 * * *$ \\
\hline Developmental milestones- 5 & 2.3 & 0.32 & 2.8 & 0.09 & $3.92 * * *$ \\
\hline Developmental milestones- 6 & 2.4 & 0.33 & 2.9 & 0.06 & $5.08 * * *$ \\
\hline Diet during early childhood & 2.1 & 0.29 & 2.9 & 0.06 & $9.20 * * *$ \\
\hline Hygiene & 2.4 & 0.34 & 2.8 & 0.09 & $2.60 * *$ \\
\hline ORS & 2.4 & 0.33 & 2.8 & 0.06 & $3.14 * *$ \\
\hline Diet during convalescence & 2.4 & 0.34 & 2.9 & 0.05 & $3.77 * * *$ \\
\hline Hygiene during diarrhea & 2.4 & 0.34 & 2.8 & 0.08 & $3.32 * *$ \\
\hline Weaning food production & 2.3 & 0.32 & 2.8 & 0.06 & $4.49 * * *$ \\
\hline Weaning food utilization & 2.2 & 0.31 & 2.7 & 0.08 & $4.69 * * *$ \\
\hline \multicolumn{6}{|l|}{ High Baseline Scores } \\
\hline Diet during diarrhea & 2.64 & 0.37 & 2.84 & 0.07 & 1.45 \\
\hline Breast feed during diarrhea & 2.64 & 0.37 & 3 & 0.00 & $2.68 * *$ \\
\hline \multicolumn{6}{|l|}{ Low Baseline Scores } \\
\hline Use of iron and folate tablets & 1.88 & 0.26 & 2.8 & 0.08 & $11.75 * * *$ \\
\hline Appropriate weight-for-age & 1.88 & 0.26 & 2.4 & 0.09 & $6.33 * * *$ \\
\hline Developmental milestones- 1 & 1.88 & 0.26 & 2.8 & 0.08 & $11.759 * * *$ \\
\hline Developmental milestones-2 & 1.92 & 0.27 & 2.8 & 0.08 & $10.80 * * *$ \\
\hline Dehydration of LGLV & 1.96 & 0.27 & 2.9 & 0.06 & $12.47 * * *$ \\
\hline Quick method of dehydration & 1.96 & 0.27 & 2.7 & 0.08 & $9.01 * * *$ \\
\hline Utilization of dry LGLV & 1.92 & 0.27 & 2.9 & 0.05 & $13.14 * * *$ \\
\hline Use of iron utensils & 1.76 & 0.24 & 2.9 & 0.04 & $19.00 * * *$ \\
\hline
\end{tabular}

$* *-\mathrm{P}<0.1 ; * * *-\mathrm{P}<0.01$

questions is depicted in Table 2 and 3 , respectively. The difference in the baseline levels of knowledge between the two groups was not statistically significant. Overall means of scores obtained indicate that there was a significant change in the post-intervention level of knowledge in the groups after reading the booklet. Gains were more in the Group-B women as they had higher knowledge gaps when compared to Group-A women who were undergoing on campus training.

Baseline knowledge levels for different messages were different. Therefore, the messages grouped into three categories to assign degree of emphasis that needs to be placed on different areas of nutrition education. First category consisted of messages for which mean scores were less than two, these correspond to either no knowledge, and second category consisted of messages for which mean scores were greater than two Baseline scores obtained by two categories were significantly different. Maximum gains in knowledge levels were seen for variables, which were included in the low-level category.

It was observed that highly significant $(\mathrm{P}<0.001)$ improvements in knowledge were observed in 23 out of 31 variables in Group-A and in all variables in Group-B.For other variables also significant improvements $(\mathrm{P}<0.1$ or 0.5$)$ were observed. Educational level of women showed positive correlation with the post-intervention scores in Group-A and Group-B(r=0.49; 0.42; $\mathrm{P}<0.01)$.Results of the present study confirm the findings of Joshi and Singh (2002).

The variables included in this study are in keeping with strategies and intervention for improving maternal nutrition suggested by Ramachandran (1994). The base line scores in this 
Table 3: Mean scores of knowledge levels of young rural women of Kurubarahalli $(n=27)$

\begin{tabular}{|c|c|c|c|c|c|}
\hline \multirow[t]{3}{*}{ Baseline scores } & \multicolumn{4}{|c|}{ Scores of Group B } & \multirow[b]{3}{*}{ ' $t$ ' value } \\
\hline & \multicolumn{2}{|c|}{ Base Line } & \multicolumn{2}{|c|}{ Post-Intervention } & \\
\hline & Mean & $S E$ & Mean & $S E$ & \\
\hline \multicolumn{6}{|l|}{ Medium Baselines Scores } \\
\hline Use of iron and folate tablets & 2.0 & 0.09 & 2.8 & 0.07 & $7.42 * * *$ \\
\hline Tetanus shots in pregnancy & 2.2 & 0.09 & 3.0 & 0.00 & $8.87 * * *$ \\
\hline Health check-ups in pregnancy & 2.5 & 0.09 & 2.6 & 0.11 & 0.94 \\
\hline Birth Spacing & 2.0 & 0.10 & 2.6 & 0.08 & $4.60 * * *$ \\
\hline Diet in pregnancy & 2.1 & 0.10 & 3.0 & 0.00 & $8.73 * * *$ \\
\hline First breast feed & 2.5 & 0.07 & 3.0 & 0.00 & $6.43 * * *$ \\
\hline Complementary feeding & 2.2 & 0.090 & 2.7 & 0.08 & $4.12 * * *$ \\
\hline On-demand breast feeding & 2.3 & 0.12 & 2.8 & 0.08 & $3.37 * *$ \\
\hline Immunization Schedule & 2.2 & 0.11 & 2.6 & 0.09 & $2.89 * *$ \\
\hline Birth Weight & 2.0 & 0.07 & 2.8 & 0.08 & $6.71 * * *$ \\
\hline Developmental milestones-5 & 2.1 & 0.06 & 2.5 & 0.12 & $3.42 * *$ \\
\hline Developmental milestones- 6 & 2.0 & 0.09 & 2.8 & 0.08 & $6.92 * * *$ \\
\hline Hygiene & 2.1 & 0.13 & 3.0 & 0.03 & $6.26 * * *$ \\
\hline Diet during diarrhea & 2.2 & 0.11 & 2.9 & 0.05 & $5.66 * * *$ \\
\hline Breast feeds during diarrhea & 2.1 & 0.11 & 2.7 & 0.09 & $4.46 * * *$ \\
\hline ORS & 2.2 & 0.10 & 2.9 & 0.04 & $6.59 * * *$ \\
\hline Hygiene during diarrhea & 2.0 & 0.09 & 2.9 & 0.06 & $8.04 * * *$ \\
\hline Weaning food production & 2.5 & 0.08 & 3.0 & 0.03 & $5.70 * * *$ \\
\hline Weaning food utilization & 2.2 & 0.08 & 2.9 & 0.06 & $6.54 * * *$ \\
\hline Utilization of dry LGLV & 2.0 & 0.00 & 2.9 & 0.04 & $22.28 * * *$ \\
\hline Use of iron utensils & 2.0 & 0.00 & 3.0 & 0.00 & - \\
\hline \multicolumn{6}{|l|}{ Low Baseline Scores } \\
\hline Immunization Schedule & 1.8 & 0.05 & 2.8 & 2.8 & $11.30 * * *$ \\
\hline Estimation of child's weight & 1.6 & 0.09 & 2.4 & 2.4 & $6.26 * * *$ \\
\hline Appropriate weight-for-age & 1.6 & 0.08 & 2.1 & 2.1 & $4.03 * * *$ \\
\hline Developmental milestones- 1 & 1.8 & 0.08 & 2.7 & 2.7 & $7.6 * * *$ \\
\hline Developmental milestones- 2 & 1.8 & 0.07 & 2.7 & 2.7 & $8.81 * * *$ \\
\hline Developmental milestones- 3 & 1.9 & 0.08 & 2.7 & 2.7 & $6.93 * * *$ \\
\hline Diet during early childhood & 1.7 & 0.14 & 2.9 & 2.9 & $7.47 * * *$ \\
\hline Diet during convalescence & 1.9 & 0.07 & 2.6 & 2.6 & $6.22 * * *$ \\
\hline Dehydration of LGLV & 1.9 & 0.05 & 2.9 & 2.9 & $13.65 * * *$ \\
\hline Quick method of dehydration & 1.9 & 0.04 & 2.5 & 2.5 & $5.38 * * *$ \\
\hline
\end{tabular}

$* *$ - $\mathrm{P}<0.1 ; * * *$ - $\mathrm{P}<0.01$

study in all groups confirms the opinion of several workers that population has inadequate nutrition knowledge (Ramji 1994). The high post intervention scores suggest that the nutrition education was effective in improving knowledge levels as the focus was in line with existing beliefs and needs of the community as suggested by Suttilak et al (1993).Overall, the study confirms and emphasizes the need for effective nutrition education to eradicate existing malnutrition.

\section{REFERENCES}

Anderson AS, Campbell DM, Shepherd R 1995. The influence of dietary advice on nutrient intake during pregnancy. British J of Nutrition, 73(2): 163-177.

Bhat IA, Shah GN, Dhar GM, Mehnaz S 1992. A study on impact of maternal knowledge and practice on the nutritional status of infants. Indian Journal of National and Child Health, 3(1): 12-15.
Buyekx M 1993. The international community's commitment to combating micronutrient deficiencies. Food, Nutrition and Agriculture, 7: 2-7.

Deshpande S, Bargale PC 2006. Impact of Nutrition education on intake of soybased food.The Ind $J$ Nutr Dietet, 43: 245-250.

Dyson DC, Crites YM, Ray DA and Armstrong MA 1991. Prevention of preterm birth in high risk patients: The role of education and provider contact versus home uterine monitoring. Am J Obstet Gynecol, 164: 756-762.

Gillespie S 1994. Nutrition surveillance for action, In: HPS Sachdev, P Choudary (Eds.): Nutrition in Children Developing Country Concerns. National update on Nutrition in Children, pp. 433-442.

Joshi N, Singh RR 2002. Development and evaluation of education material for nutrition education. Indian $J$ Nutr Dietet, 39(8): 373-378.

Kafatos AG, Vlachonikolis JG, Cadrington CA 1989. Nutrition during pregnancy: The effects of an educational intervention program in Greece. Am $J$ Clin Nutr, 50: 970-979.

Kaur N, Chawla P 2006. Impact of Nutrition Counseling 
on the knowledge, attitude and practice scores of at risk coronary hear disease subjects. The Ind $J$ Nutr Dietet, 43: 82-88.

Nayak UM, Vijayaraghavan K, Vazir S, Chandralekha K 1999. Foundation of messages for effective communication. In: National Seminar on Initiatives in Nutrition and Health Education Problems and Prospects, $29^{\text {th }}-30^{\text {th }}$ October, Tirupati.

Ramachandran P 1994. Strategies and interventions for improving maternal nutrition: Changing concepts and current concerns. In: HPS Sachdev, Panna Choudary (Eds.): Nutrition in Children Developing Country concerns. New Delhi: NUNC MAM College, Delhi, Cambridge Press, pp. 470-481

Ramji S 1994. National Nutrition Policy. A summary of important aspects. In: HPS Sachdev, SP Choudary (Eds.): Nutrition in Children-Developing Country Concerns. New Delhi: NUNC MAM College, Delhi, Cambridge Press, pp. 413-446.

Saibaba A, Raghuram TG 1999. Nutrition educatin. In: National Seminar on Initiatives in Nutrition and Health Education-Problems and Prospectus. October 29-30, P.P.M.V.V.Tirupati, India.

Suttilak S, Attig GA, Valya sevi A, Dhanamitta S, Tontisirin K 1993. Social Marketing Vitamin A Rich Foods in Thailand-A Model Nutrition Communication for Behaviour Change Process) Salaya, PNP 73170, Thailand: The Institute of Nutrition, Mahidol University (INMU) 